\title{
Research on the Normalized Online Teaching Strategies of Ordinary Universities in the Post- Epidemic Era
}

\author{
Xiaofang Zhao*, Shuying Chen \\ School of Computer Science and Technology, Shandong Technology and Business University, Yantai, China \\ "Corresponding author. Email: xf_zh@163.com
}

\begin{abstract}
Under the normalization of epidemic prevention and control, it is imperative to implement normalized online teaching in Colleges and universities. In the post-epidemic era, the implementation of normalized online teaching in ordinary universities can take the construction of blended curriculum as the handle and construct through the "Trinity" linkage mode. In order to promote the implementation of normalized online teaching, a series of strategies can be put forward, such as strengthening the construction of blended curriculum, bringing online courses into the talent training program, implementing long-term training of teachers' information teaching, optimizing the teaching organization form, cultivating students' self-learning ability and so on.
\end{abstract}

Keywords: Online Teaching, Post-epidemic Era, Normalization, Ordinary Universities, Construction of Blended Curriculum.

\section{INTRODUCTION}

The concept of online teaching has been put forward as early as 2008 , and has been vigorously developed since 2012. The COVID-19 has pushed online teaching to a new upsurge. Under the background of unable to start school normally, online teaching is imperative. It can easily cross the limitation of time and space and then to realize the remote teaching and learning. In view of the fact that teachers and students have gradually adapted to online teaching, ordinary universities should seize the opportunity to change "danger" into "opportunity" in the post- epidemic era. Then, they should vigorously promote teaching reform to accelerate the process of information and digitization education. Specially, it should be to integrate online teaching with traditional teaching, and make online teaching normalized. The effective integration of online teaching and traditional teaching is what we often call blending learning ${ }^{[1]}$. However, the blending learning in the post-epidemic era can't be compared with that before the epidemic because no online teaching has been implemented in such a wide range and with so great efforts. ${ }^{[2]}$ We have accumulated a lot of valuable experience of online teaching during the epidemic. Taking advantage of the experience and applying it to normal teaching activities is very necessary.

\section{THE FEASIBILITY OF IMPLEMENTING NORMALIZED ONLINE TEACHING IN ORDINARY UNIVERSITIES}

\subsection{Using Habits}

Before the epidemic, Students in ordinary universities accept using online teaching mainly in training courses, and they are biased against teachers' use of online teaching in the classroom. Teachers in ordinary universities also don't take full advantage of using online teaching. Online teaching is only used as an auxiliary tool for classroom teaching. The main reason of that online teaching was not fully utilized before the epidemic is that we did not have much experience in using it. The use of online teaching during the epidemic period made us fully realize the advantages of online teaching, such as it can not only break the limitation of time and space but also provide more abundant and diverse learning resources, students can be more free and independent in learning, the communication and interaction between teachers and students are more timely and in-depth, teachers' attendance and homework marking are also more intelligent and so on. ${ }^{[2,3]}$ Using online teaching during 
the epidemic has changed the habits of teachers and students. So the majority of teachers and students in ordinary universities more willingly accept online teaching than before.

\subsection{Information Support Platform and Technology}

During the epidemic period, platforms and technologies supporting online teaching have been used unprecedentedly. In the process of using, many problems have also been exposed, such as server paralysis, network stuck, frequent disconnection, imperfect curriculum resources, etc. For the problems, online teaching platforms, course source construction units and internet companies have made timely improvements and adjustments. With the deepened use, teachers and students are more and more proficient in online teaching platform and tools, and all kinds of rarely used functions are also fully used. Furthermore, the supporting platform and tools provide new functions according to the use requirements. It can be said that the current online teaching platform and tools are more mature and perfect. These effectively tested information support platform and technology will be more conducive to the implementation of online teaching under normal conditions.

\section{CONSTRUCTION MODE OF NORMALIZED ONLINE TEACHING IN ORDINARY UNIVERSITIES}

In the organization of teaching activities, teachers and students are linked together by curriculum. Curriculum is starting point of teaching activities, and also the main carrier of implementing talent training tasks. The quality of curriculum affects the quality of talent cultivation. From this perspective, the implementation of normalized online teaching in ordinary universities can be carried out around the construction of blended curriculum. Then we will construct a linkage mode of "taking the blended curriculum construction as the handle and promoting the development of Trinity together". In this linkage mode, teachers, courses and students are the three main bodies. They take the construction of blended curriculum as the starting point to jointly promote the implementation of online teaching normalization. The ultimate goal is to improve the quality of talent training which is shown in Figure 1. Through the construction of blended curriculum, we can promote the ability of teachers' information teaching and the ability of students' self- learning. Furthermore we can revise the talent training plan from the construction demand and optimize the teaching organization form to strengthen the cultivation of students' effective self-learning ability. This process, in turn, still holds. In other words, this process is cyclical, which makes each link strengthen and improve, so as to promote the implementation of normalized online teaching in ordinary universities.

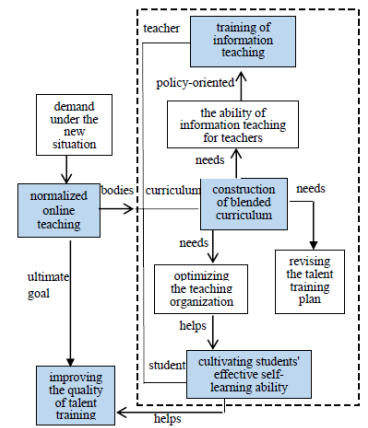

Figure 1 The trinity linkage mode of normalized online teaching

\section{STRATEGIES OF NORMALIZED ONLINE TEACHING IN ORDINARY UNIVERSITIES}

\subsection{Strengthening the Construction of Blended Curriculum and Bringing Online Courses into the Talent Training Program}

In 2019, the Ministry of education's the "Implementation Opinions on the construction of firstclass undergraduate courses" ${ }^{[4]}$ puts forward that in about three years, about 10000 national first-class undergraduate courses and about 10000 provincial-level first-class undergraduate courses will be completed. That is "Shuangwan Plan". The plan includes the construction and identification of about 6000 national online and offline mixed first-class courses. The experience of online teaching during the epidemic period made us more aware of the urgent need of blended curriculum construction. The ordinary universities should take this as the guidance. That is to say, we should carry out the blended learning mode with high quality, actively promote the construction of blended curriculum, and gradually bring the online courses into the professional training programs and teaching plans.

Through the construction of blended curriculum, it is conducive to the integration of various teaching resources and makes the structure of teaching content 
more reasonable. ${ }^{[5]}$ So it is necessary to identify and introduce high-quality online courses that meet the actual needs for the educational administration department of ordinary universities. ${ }^{[6]}$ In the postepidemic era, the online course resources introduced and self-built what were used during the epidemic period should be evaluated and screened. We should further organize teachers to optimize the selected highquality curriculum resources. And a series of measures can be taken, such as encouraging teachers to actively carry out the construction of blended curriculum, reasonably allocating the proportion of online teaching in mixed teaching, reasonably allocating the division of online teaching content and classroom teaching content, and so on. These measures can make two main lines be carried out at the same time, one of which is online teaching mode and another is traditional teaching mode. The two main lines interactive integration and play a role together.

In order to implement the normalized online teaching, online courses should be included in the talent training program, and it is also should establish connections between the online teaching content and the talent training objectives. To do that, we can achieve accurate teaching to a certain extent.

\subsection{Promoting the Long-term Training of Teachers' Information Teaching Ability}

During the epidemic period, in the beginning of online teaching, most of teachers more or less exposed the lack of information-based teaching ability, and even a large-scale "rollover accident" happened. The deep integration of educations and new technologies which including internet, cloud computing, big data, internet of things, artificial intelligence, block chain and so on, requires teachers not only to master various intelligent tools and new teaching technologies, but also to improve their own information literacy and information teaching ability. For this reason, teachers should change their concepts. That is to say, teachers should accept and approve the new teaching technologies from the essence and connotation. They also should take the new teaching technologies as a powerful tool to enrich the traditional teaching mode and improve the teaching quality. We should treat new teaching technologies correctly. We should not blindly praise them, nor simply and rudely oppose them. Some teachers are not easy to accept the new teaching technologies and they mistake them for playing videos. On the contrary, some younger teachers blindly pursue the freshness and novelty brought by new teaching technologies. They absolutely replace the traditional teaching mode with digital teaching mode. It is also not advisable. These two extreme behaviours are caused by not fully understanding the connotation of new teaching technologies.

In order to flexibly apply the new teaching technologies, it is necessary to regularly train the teachers of common universities on information teaching ability. Through the training, teachers should master what including various methods, platforms and tools of the online teaching. Firstly, their characteristics, advantages and disadvantages should be deeply understood. Then, teachers can carry out online teaching through various platforms and tools. The competent departments of ordinary universities need to formulate some policies, through which to organize and coordinate teachers to participate in the training. The policies should including rewards and punishments measures, so as to make the training to be long-term.

\subsection{Optimizing the Teaching Organization Form and Cultivating Students' Effective Self- learning Ability}

To make online teaching play an effective role, students must have a certain degree of effective selflearning ability. The self-discipline of students in ordinary universities is relatively poor, and the ability of self-learning needs teachers to strengthen and guide consciously. We should optimize the teaching organization form. Specially, we can adopt the method of "learning before teaching". According to the teaching content arrangement, students should learn the shallow knowledge by online teaching platform, and then teachers teach the deep knowledge in class. For students with poor self-learning ability, it is difficult to achieve the goal of learning without proper teaching from teachers, and will gradually lose interest in learning. In class teachers can mainly focuses on the problems in students' self-learning. The role of teachers is to help students internalize knowledge and provide professional guidance, rather than simply teach knowledge. In order to improve students' self-learning ability, it is necessary to adjust the talent training scheme to reduce the class hours, and increase the time of students' autonomous learning after class.

To cultivate students' effective self-learning ability, it needs teachers' detailed guidance at the initial stage. Teachers need to provide students with a variety of online self-learning materials, including classroom 
arrangement, learning task list, micro class, recording class, electronic version of teaching materials, reference materials, self-testing, questions, homework, etc. In the classroom arrangement and learning task list, it should be listed in detail including the whole learning arrangement, learning contents, learning objectives, achievement standards and learning requirements and so on. After students have certain self-learning ability, teaching organizations should focus on teaching students according to their aptitude, and highlight students' personalized learning and differentiated learning. Finally, teachers should guide students to carry out deep inquiry self-learning.

\section{DESIRED RESULTS}

It is not a short-term behaviour for online teaching, it will be a long-term teaching behaviour. ${ }^{\text {[7] The }}$ implementation of normalized online teaching in ordinary universities is an effective way to comply with the trend. It is also an effective path to deeply integrate the information technology and education in the digital era.

Students of ordinary universities can easily share the courses of famous universities, which is conducive to improving the teaching quality of ordinary universities and narrowing the gap with famous ones. At the same time, it also provides the direction of education equity advocated by education information. ${ }^{[8]}$

The self-learning ability of students can be effectively improved. Then it can promote the development of students' innovation ability, improve the quality of talent training, and make the talent training meet the requirements of "new engineering", "new agriculture", "new medicine" and "new liberal arts".

The implementation of normalized online teaching can be used as an external force from the policy orientation to force teachers in ordinary universities to reform their teaching methods through integrating modern information technology. That will certainly improve teaching quality.

\section{CONCLUSION}

The online teaching under the epidemic situation has a profound impact on the teaching activities of ordinary universities. It has changed the habits of teachers and students, and further strengthened the integration of information technology and teaching. Ordinary universities should seize the opportunity to deepen teaching reform, effectively integrate online teaching and classroom teaching, normalize online teaching, and transform "wartime measures" into "peacetime mechanism", so as to improve the quality of teaching and personnel training, and ultimately improve the competitiveness of school.

\section{REFERENCES}

[1] Shengquan Yu, Qiuli Lu, Shengjian Chen, The blending learning under NetWork environment-a new teaching mode, in: China University Teaching, vol. 10, Beijing, China, 2005, pp.50-56.

[2] Jianli Jiao, Xiaoqing Zhou, Zexuan Chen, Case Analysis of the Online Instruction in the Context of "Classes Suspended but Learning Continues" for Plague Prevention, in: Yaxuan Li (Eds.), China EEducation, vol. 398, Beijing, China, 2020, pp.106113.

[3] Ying Wang, The reform and innovation in higher education teaching of the digital era, in: Guangbin Shen(Eds.), Jiangsu Higher Education, vol.9, Nanjing, China, 2019, pp.72-77. DOI: 10.13236/j.cnki.jshe.2019.09.012

[4] Ministry of Education, Opinions of the ministry of education on the construction of first class undergraduate courses, China, [EB/OL]. http://www.moe.gov.cn/srcsite/A08/s7056/201910/ t20191031_406269.html,2019-11-12

[5] Fengqing Li, Xinhua Wang, Jianmin Zhao, Toplevel design and implementation strategy for the blended curriculum construction project, in: Xiao Xi (Eds.), Modern Educational Technology, vol.6, Beijing, China, 2018, pp.32-38. DOI: 10.3969/j.issn.1009-8097.2018.06.005

[6] Xiaohong Yang, Haijun Zhou, Xiaozhang Zhou, Research on the construction of the criteria for identifying teaching quality of online Open courses in universities, in: Yaxuan Li (Eds.), China EEducation, vol. 397, Beijing, China, 2020, pp.6774.

[7] Ruihong Zhang, Online teaching is a long-term teaching revolution, in: China Science Daily, Beijing, China, 2020-02-18.

[8] Chaozi Lei, Support and lead the modernization of education with e information education, in: China Teacher Daily, Beijing, China, 2018-01-03. 